\title{
Increasing the Efficiency of Grid Tied Micro Wind Turbines in Low Wind Speed Regimes
}

\author{
Kshitij Tiwari ${ }^{1,2}$, Tirumalachetty Harinarayana ${ }^{2}$ \\ ${ }^{1}$ Department of Electrical Engineering, Indian Institute of Technology, Kanpur, India \\ ${ }^{2}$ Gujarat Energy Research and Management Institute, Gandhinagar, India \\ Email: kshitij537@gmail.com, harinarayana@germi.res.in
}

Received 15 August 2014; revised 10 September 2014; accepted 16 September 2014

Copyright (C) 2014 by authors and Scientific Research Publishing Inc.

This work is licensed under the Creative Commons Attribution International License (CC BY).

http://creativecommons.org/licenses/by/4.0/

(c) (i) Open Access

\begin{abstract}
Major problem with grid tied micro wind turbine is synchronization and wind variability. Due to this problem the stability of available grid gets reduced. The stability can be achieved by output power control of the turbine. Major part of many countries like India, the annual mean wind speed is not high. The rated wind speed of turbine remain around $11 \mathrm{~m} / \mathrm{s}$ and cut in is around $3.5 \mathrm{~m} / \mathrm{s}$. Due to this problem we aimed to develop a sustainable wind energy system that can provide stable power supply even at the locations of low wind speed of $2-4 \mathrm{~m} / \mathrm{s}$. To address this issue, a momentary impulse or external torque to the rotor by external motor is one of the good options to maintain the momentum of blades and thus provide stability for sufficient time. Various theoretical calculations and experiments are conducted on the above method. This would increase the output power and also the efficiency of wind turbine. We show that Return-On-Investment will be high as compared with other grid connected turbines. Our proposed concept in the present study, if implemented properly, can help the installation of number of wind turbines even at domestic level. It also makes the consumers energy independent and promotes the use of wind as a source of energy and may enter as a rooftop energy supply system similar to solar.
\end{abstract}

\section{Keywords}

Grid Tied Rooftop Micro Wind Turbine, Small External DC Motor, Wind Variability, Tip-Speed Ratio (TSR), Stabilized Grid Supply

\section{Introduction}

Wind energy development is picked up as a part of electricity generation in different parts of India. Although it was initiated a decade back, there is still enough scope for its improvement in this technology. The reality is that our life-style in the early twenty-first century requires huge energy and wind turbines are one of the least envi- 
ronmentally harmful ways of generating electricity. Of the installed capacity, wind turbines have a large share among the other grid connected renewable sources, close to $66.66 \%{ }^{1}$. Obviously wind turbines need to be built where the wind blows reliably and strongly. The society is certainly not willing to give up private cars, air conditioning, computers, television, refrigeration, and all the other energy consuming equipment of the modern life-style. Accordingly, we must build sustainable energy supply systems. Earlier works promoted wind energy in many ways [1] [2]. In our study we have worked on grid tied rooftop micro wind turbine. The major problem with such a system is synchronization largely due to wind variability. Due to this problem, the stability of available grid gets reduced. This can somehow be achieved by the output power control of the turbine. India is the fifth largest wind power producer in the world. As of March 2014, the installed capacity of wind power in India is 21136.3 MW [3] [4], mainly spread across Tamil Nadu (7154 MW), Gujarat (3093 MW), Maharashtra (2976 MW), Karnataka (2113 MW) and Rajasthan (2355 MW). Wind power accounts for 8.5\% of India's total installed renewable power capacity, and it generates $1.6 \%$ of the country's power. Still it is not very much popular at domestic level due to the high initial investment and other problems as discussed above. Our goal is to achieve stable power supply to the grid from wind source. To this issue, we suggest a new method of small external motor that will provide momentary impulse or external torque to the rotor through relay switch or voltage controller that helps to maintain the momentum of blades for sufficient time and provide stable power supply. In this method, the light weight external motor has been attached at the hub of the wind turbine and it works on the method of spring balance system. The motor aligns itself with the axis of rotation of blades when a mass of around 10 pounds is put to the groove attached to motor. This is done so as to not disturb the aerodynamics of the blades and the yaw system. The motor provides external torque to the rotor only during moderately low wind speeds, i.e., around $2.5-4 \mathrm{~m} / \mathrm{s}$. At other times, when the wind speed is self sufficient to produce stable power supply, the motor remains off-axis from the rotor and doesn't interfere in its motion. This mechanism is currently mechanical but could be automated for better performance. The concept presented in this paper is implemented and tested.

\section{Materials and Methods}

In our method, we attached an external motor to the turbine rotor that provides sufficient external torque to the rotor to rotate at its rated rpm value when the wind speed is less than the rated speed so that the wind generator can generate a stabilized power supply.

\subsection{Theory}

It is well known that the amount of power extracted from the wind is given by the equation:

$$
\begin{aligned}
& P_{\text {Wind }}=\frac{1}{2} \rho A V^{3} C_{p} \\
& P_{\text {Generated }}=\frac{1}{2} \rho \pi R^{2} V^{3} C_{p} C_{t} C_{g}\left(\frac{p}{2}\right)[5]-[7]
\end{aligned}
$$

$$
\text { Tip Speed Ratio }(\lambda)=\frac{\omega R}{V}[5]-[7]
$$

where, $P_{\text {Wind }}=$ Power Delivered by Wind to the rotor below the rated value, $P_{\text {Generated }}=$ Output Power of the generator, $C_{p}=$ Power Coefficient, $C_{t}=$ Transmission Coefficient, $C_{g}=$ Generator Efficiency, $p=$ Number of poles in Generator.

Motor supply sufficient torque to the rotor so that generator operates at rated power. The following is the mathematical condition:

$$
\begin{aligned}
& \tau_{\text {Wind }}+\tau_{\text {Motor }}=\tau_{\text {Rated }} \\
& \frac{P_{\text {Wind }}}{\omega_{\text {Rotor }}}+\frac{P_{\text {Motor }}}{\omega_{\text {Motor }}}=\frac{P_{\text {Rated }}}{\omega_{\text {Rated }}}
\end{aligned}
$$

http://www.re-solve.in/wp-content/uploads/2014/05/Installed-capacity-31March-2014.png 


$$
\frac{\frac{1}{2} \rho \pi R^{2} V_{\text {Wind }}^{3} C_{P}}{\omega_{\text {Rotor }}}+\frac{P_{\text {Motor }}}{\omega_{\text {Motor }}}=\frac{\frac{1}{2} \rho \pi R^{2} V_{\text {Rated }}^{3} C_{P}}{\omega_{\text {Rated }}}
$$

Using Equation (3)

$$
P_{\text {Motor }}=\frac{1}{2} \frac{\rho \pi R^{3} C_{P}\left(V_{\text {Rated }}^{2}-V_{\text {Wind }}^{2}\right) \omega_{\text {Motor }}}{\lambda}
$$

For the above suggested mechanism to be useful, the generated power should be greater than the power supplied by the motor:

$$
\begin{gathered}
P_{\text {Generated }} \geq P_{\text {Motor }} \\
V_{\text {Rated }}^{3} C_{t} C_{g}\left(\frac{p}{2}\right) \geq \frac{R \omega_{\text {Motor }}}{\lambda}\left(V_{\text {Rated }}^{2}-V_{\text {Wind }}^{2}\right)
\end{gathered}
$$

In our study, SNT-1 ${ }^{2} 700 \mathrm{~W}$ micro grid tied turbine is used. Its parameters are, $V_{\text {Rated }}=11 \mathrm{~m} / \mathrm{s}$ (according to industry standards), $C_{t}=1$ (since no gearbox system is used), $C_{g}=0.25$ (assumed to be constant for easier calculations), $C_{P}=0.33$ (assumed to be constant), $p=8, R=920 \mathrm{~mm}, V_{\text {Cut-in }}=2 \mathrm{~m} / \mathrm{s},\left(\omega_{\text {Motor }}\right)_{\mathrm{Max}}=70 \mathrm{rpm},\left(P_{\mathrm{Motor}}\right)_{\mathrm{Max}}=$ 18 Watts.

$\mathrm{SNT}-1^{2}$ turbine is although designed for maximum rotational speed of $300 \mathrm{rpm}$ at a wind speed of $6 \mathrm{~m} / \mathrm{s}$. So, TSR $=4.81$ (assumed as constant for easier calculations) [8]-[10]. Above the wind speed of $6 \mathrm{~m} / \mathrm{s}$, it dampens extra energy to the dummy load.

Accordingly, the calculations have been carried out considering the wind speed of $6 \mathrm{~m} / \mathrm{s}$ as rated. Another reason for this is that the generator is not designed for higher wind speeds.

\subsection{Theoretical Results}

Following are the results observed by calculating using theoretical considerations:

1) Following are the results to power available to the rotor shaft at different wind speeds (Figure 1);

2) Following is the plot of external torque to be provided by motor to achieve the rated rpm (Figure 2). Maximum torque that can be provided by our installed DC Motor is $2.45 \mathrm{~N}$-m. In the Figure 2 green region corresponds to desirable region of operation and red region corresponds to undesirable operational region.

\subsection{Experimental Results}

1) An experiment with power output is conducted on $700 \mathrm{~W}$ SNT-1 micro wind turbine at the premises of

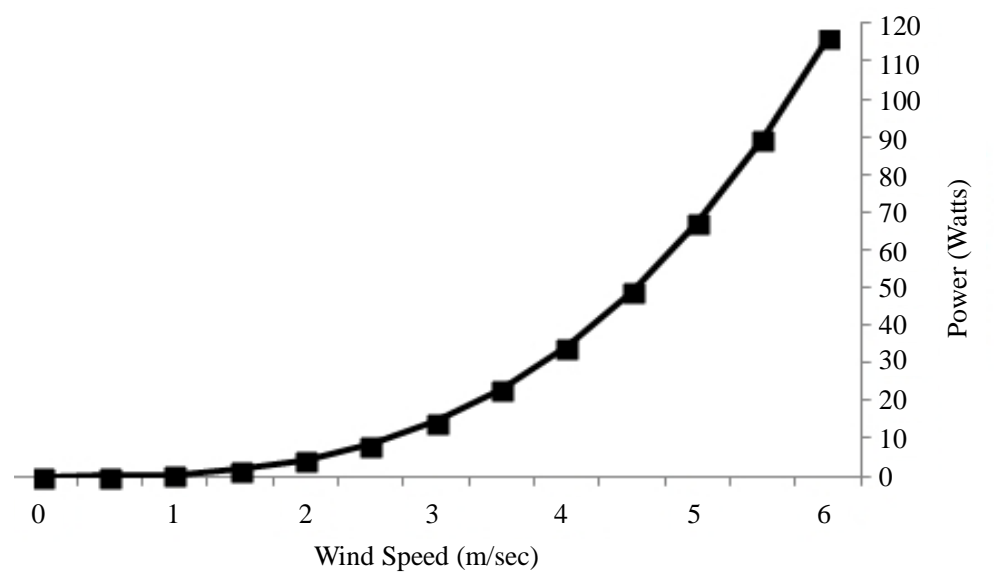

Figure 1. Available rotor power at various wind speeds.

${ }^{2}$ SNT-1 Wind Turbine: Supernova Technologies Pvt. Ltd. Turbine Model No.1 (Figure 10). 
SNT Unit, Udyognagar, Anand, Gujarat and a comparative study of theoretical [11]-[13] and practical results are shown in Figure 3.

2) However in a controlled environment on a test bench of SNT, a 3HP motor is used to rotate the shaft of 400 $\mathrm{W}$ generator. The results obtained are contradictory to our theoretical results. We obtained power consumed is greater than power generated for every value of generator rpm. However, this is not our intention to do, because, the entire energy to rotate the generator shaft is provided by motor in this case. In our method, partial energy would be provided by the wind. Experimental results using external motor without wind are as shown below (Figure 4 \& Figure 5).

3) When the above curve of power generated was studied at various equivalent wind speeds (assuming TSR as constant according to the rated value) following results were obtained (Figure 6).

4) Experiment is conducted on Rooftop Wind SNT-1 Wind Turbinein normal mode with low wind speed. Grid Tied Rooftop Windmill installed on the rooftop of GERMI is SNT-1 Wind Turbine with generator Rated Power of $700 \mathrm{~W}$ and external Motor Rated Power of $18 \mathrm{~W}$. Results obtained are as follows (Figure 7).

5) In another experiment on SNT-1 Rooftop wind turbine at GERMI, it is observed that power consumed by motor is much higher compared to power generated by the turbine. This is due to the fact that the rotor is purely running on motor and there is no effect of wind on rotor when the motor is in switched on mode. This is due to the current mechanism of spring balance which is being used to align motor with generator axis which prohibits any affect of wind on rotor. Experimental results when the external motor is used are as follows (Figure 8).

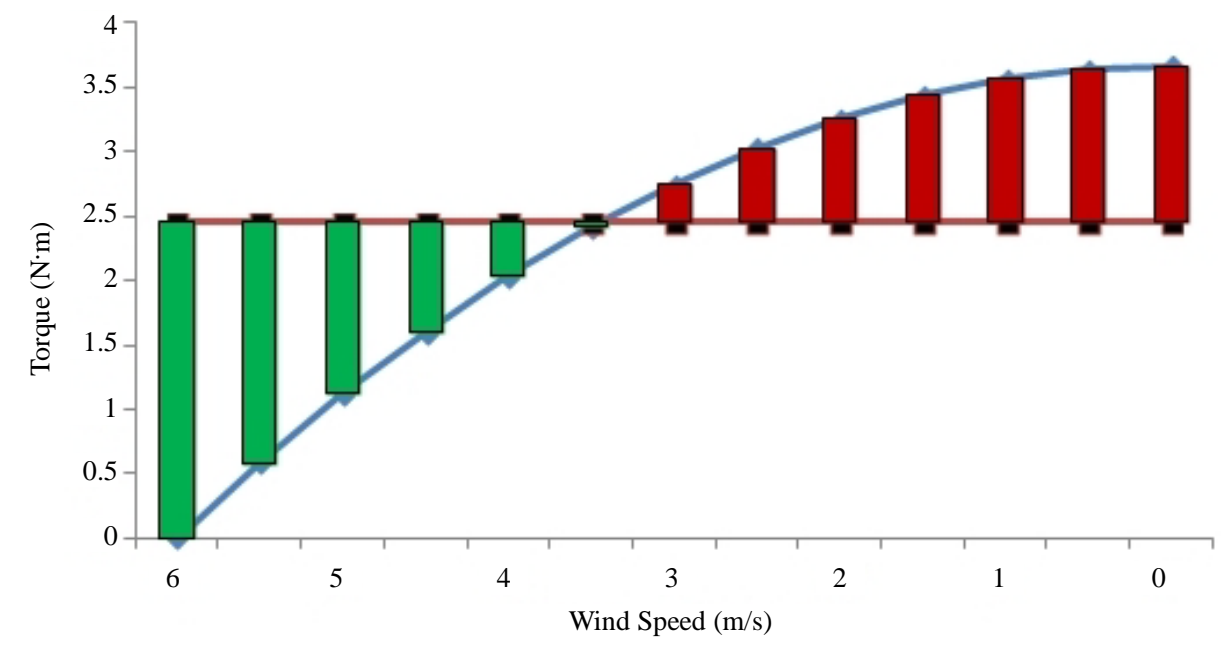

Figure 2. Torque to be provided by external motor at various wind speeds.

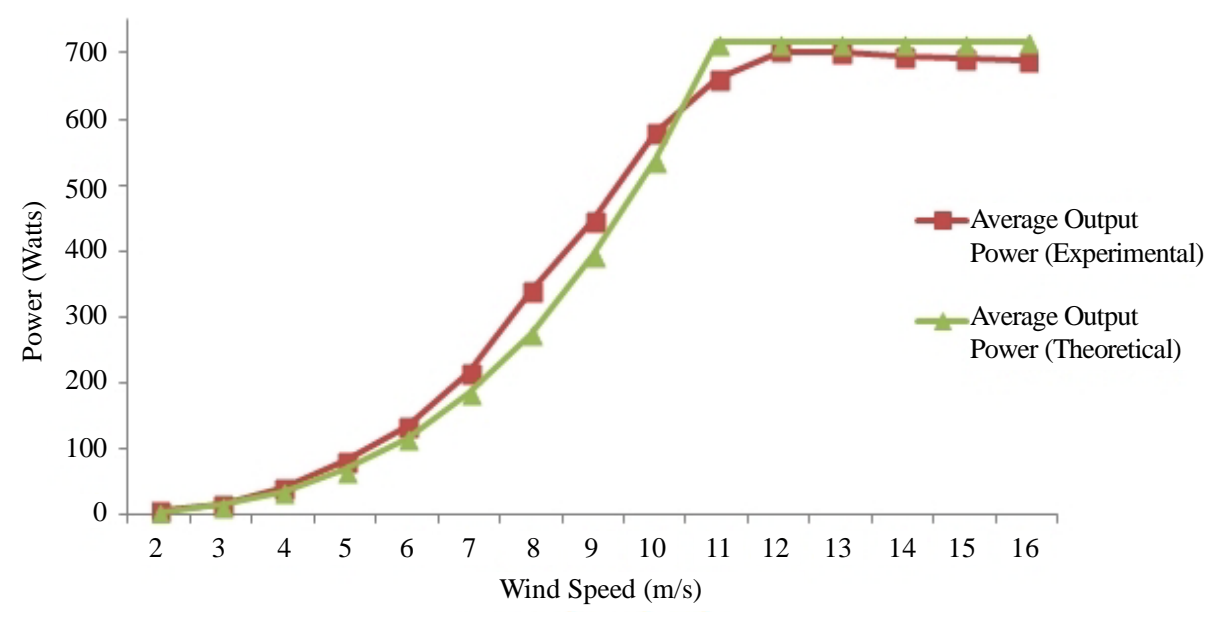

Figure 3. Comparative study of average output power (theoretical \& experimental). 


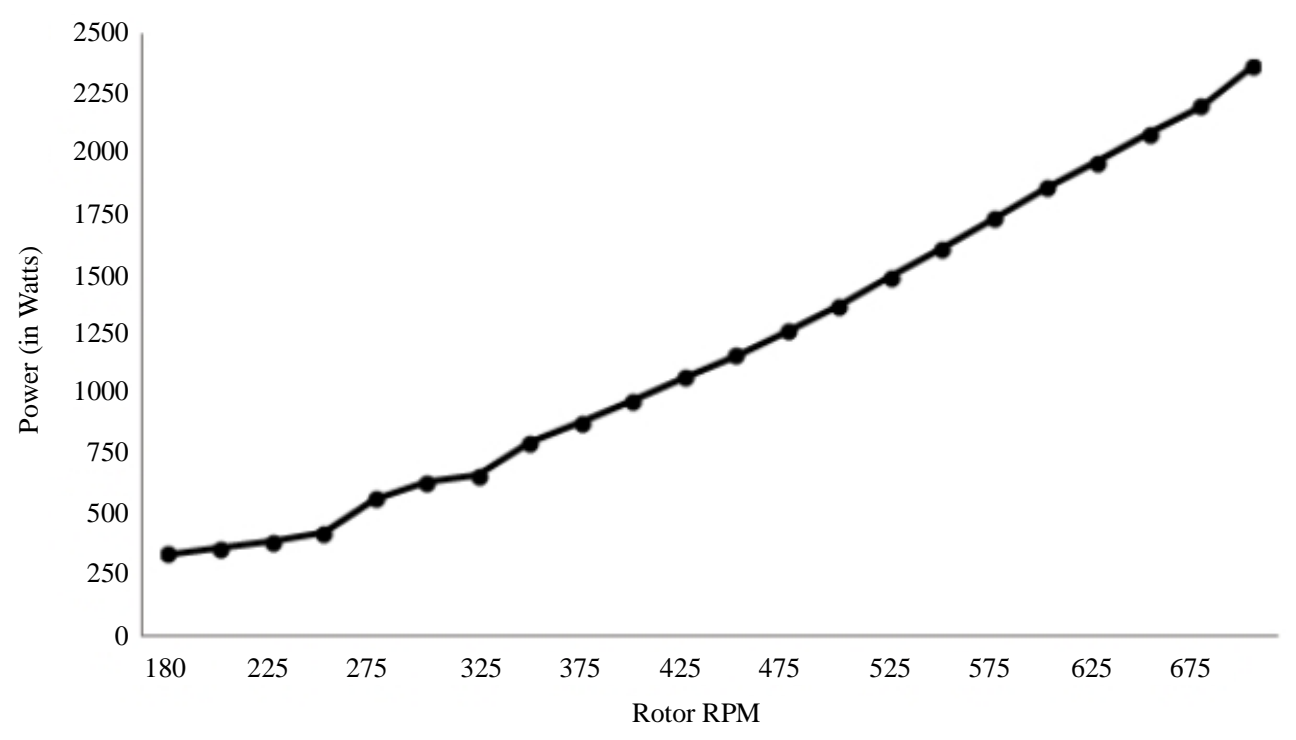

Figure 4. Power consumed by motor at various rotor RPM.

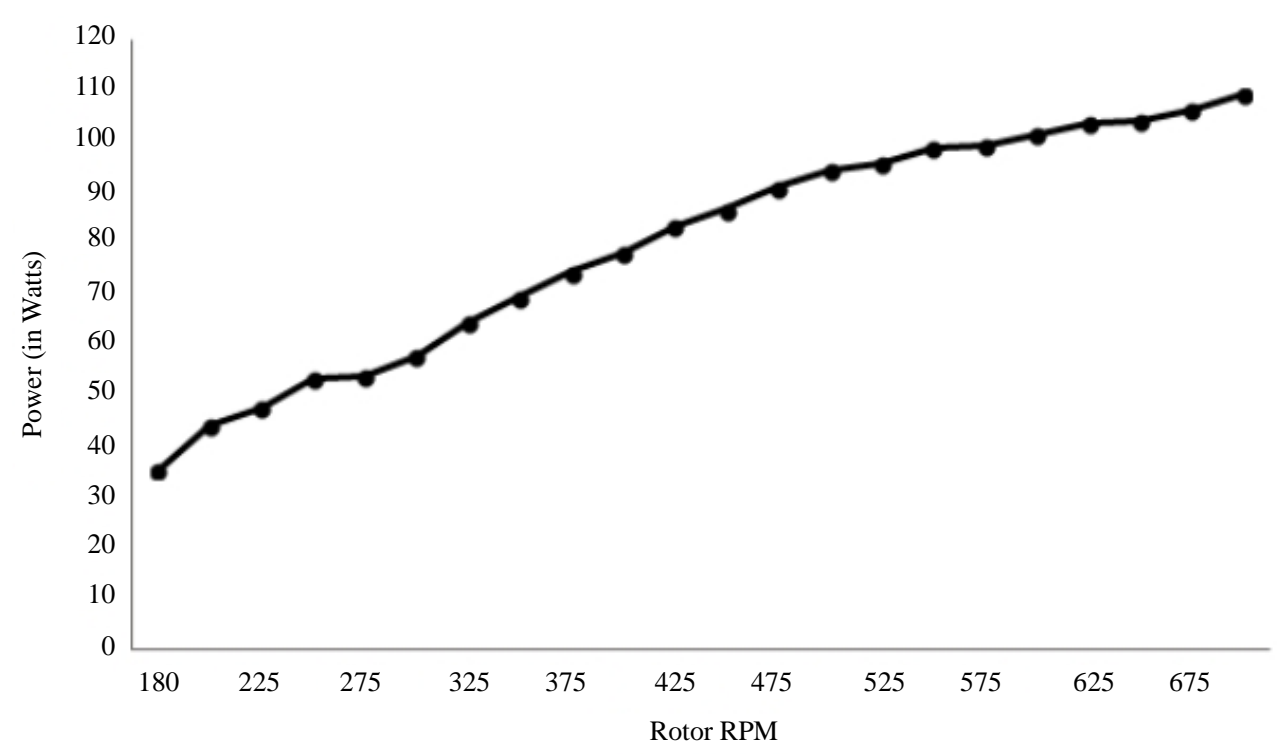

Figure 5. Power generated by generator at various rotor RPM.

\subsection{Theoretical Power Gain}

The results in Figure 9 are obtained on comparing the results of power generated and power consumed for live wind speed data.

The wind data is recorded for every 2 minutes and the difference between the the two curves actually demonstrate the net power produced by the wind turbine system. The above results clearly show that we gain power in our discussed method and hence our method proves to be fruitful theoretically whereas the experimental feasibility has been partially established but it is yet to be worked upon more extensively.

\section{Conclusions}

We have addressed a few issues related to wind turbines and suggested solutions for the same. Hopefully our suggested method will yield into a product that would help changing the wind power scenario at domestic level. SNT-1 wind turbine installed on rooftop of our energy building — GERMI at PDPU campus (Figures 10-12) —is 


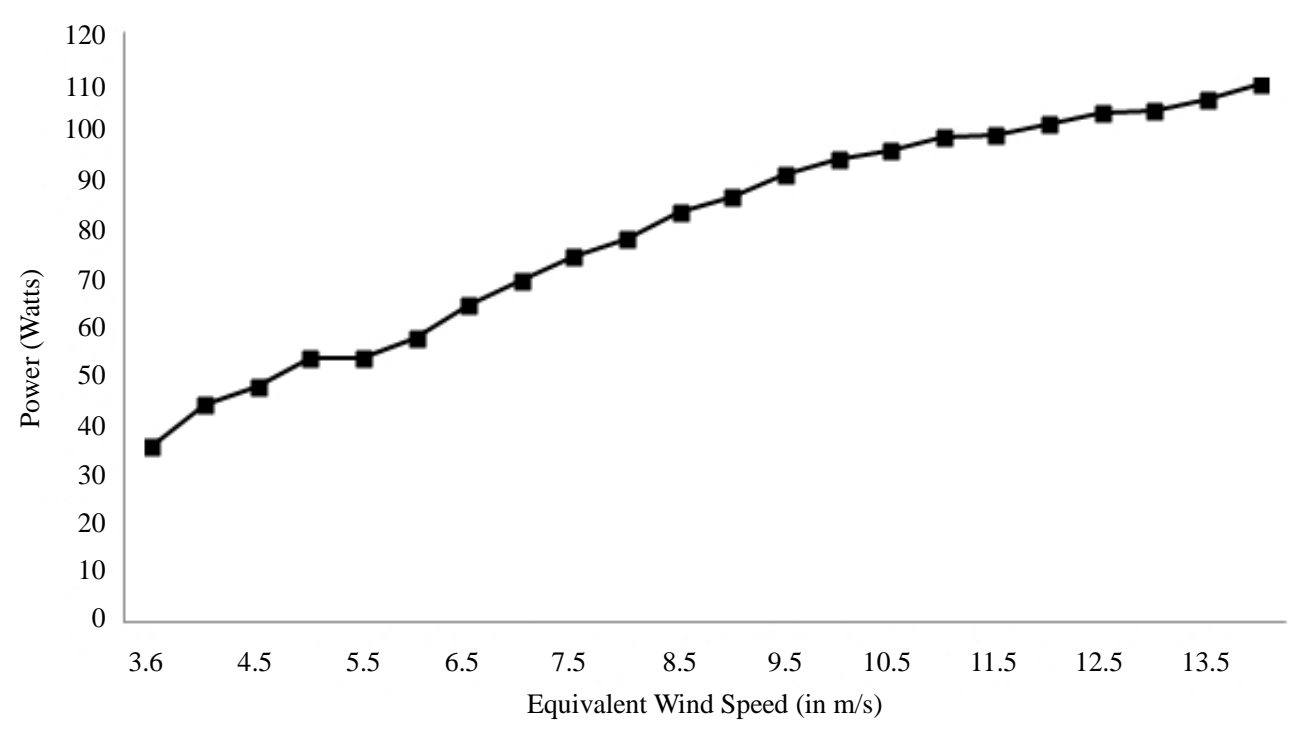

Figure 6. Power generated by generator at various equivalent wind speeds.

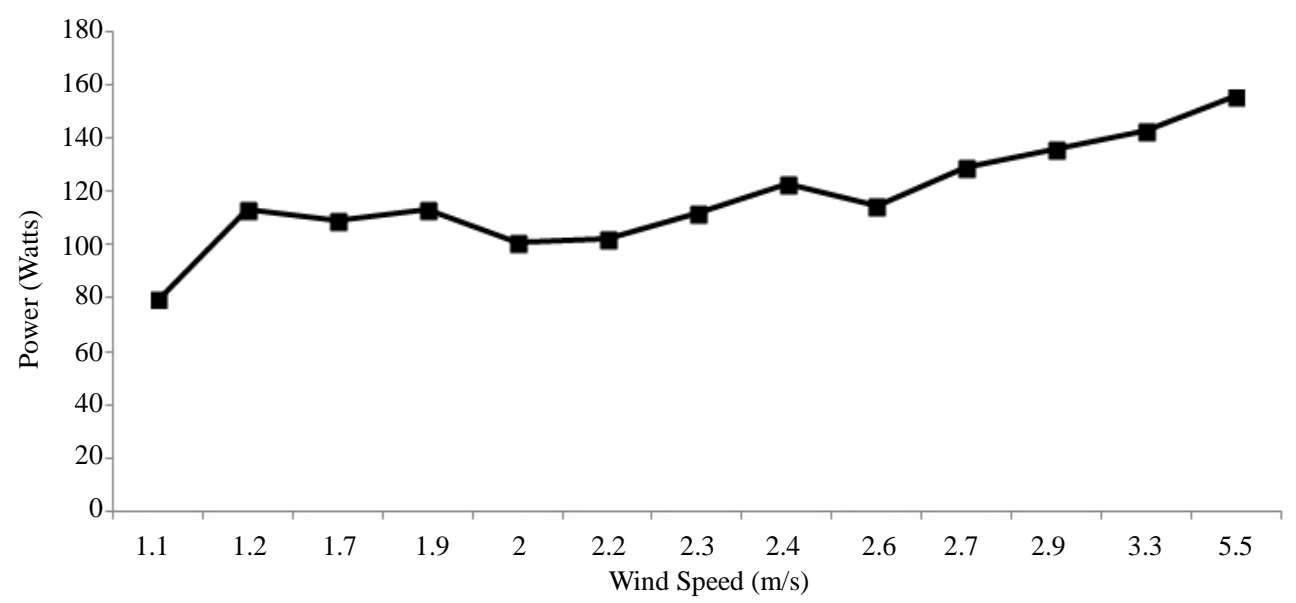

Figure 7. Power generated at various wind speeds (site results).

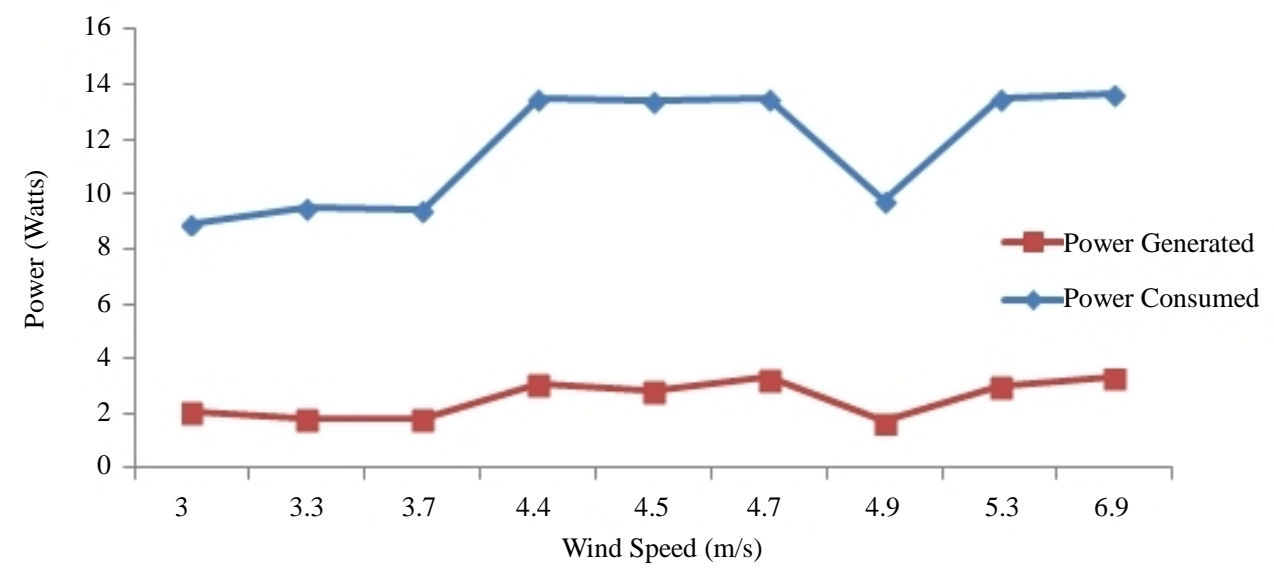

Figure 8. Power generated and consumed at various wind speeds. 


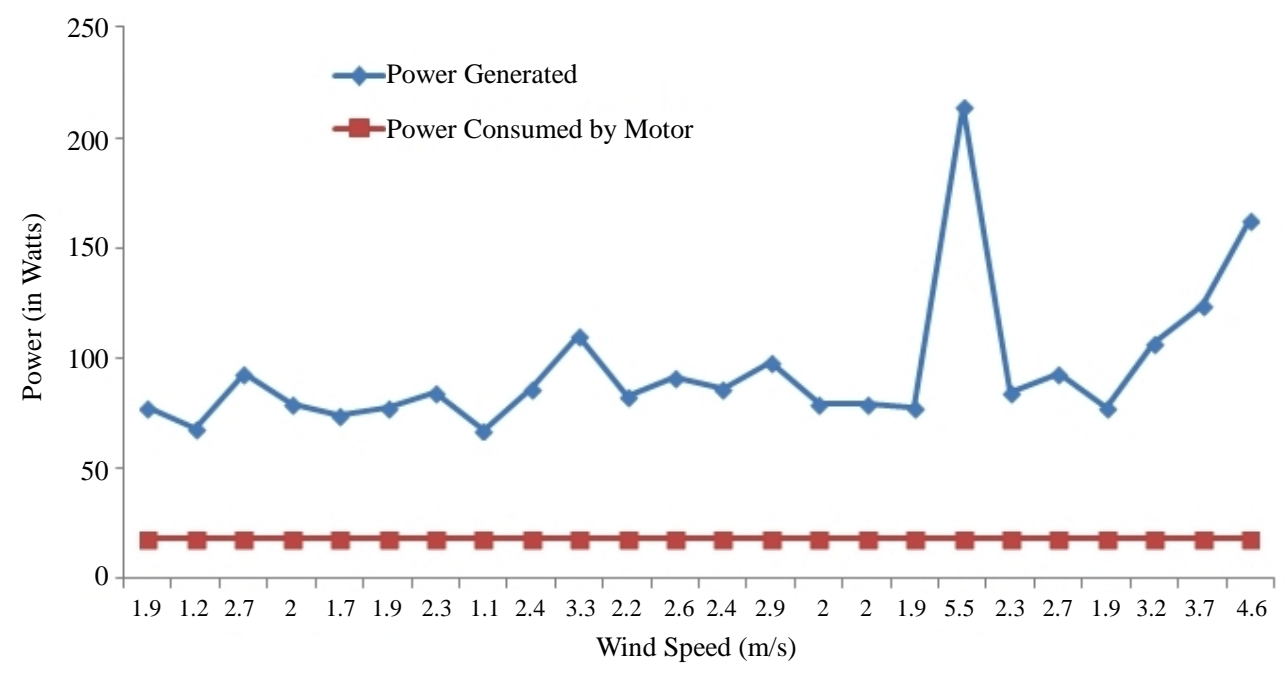

Figure 9. Power generated and consumed at live wind speeds.

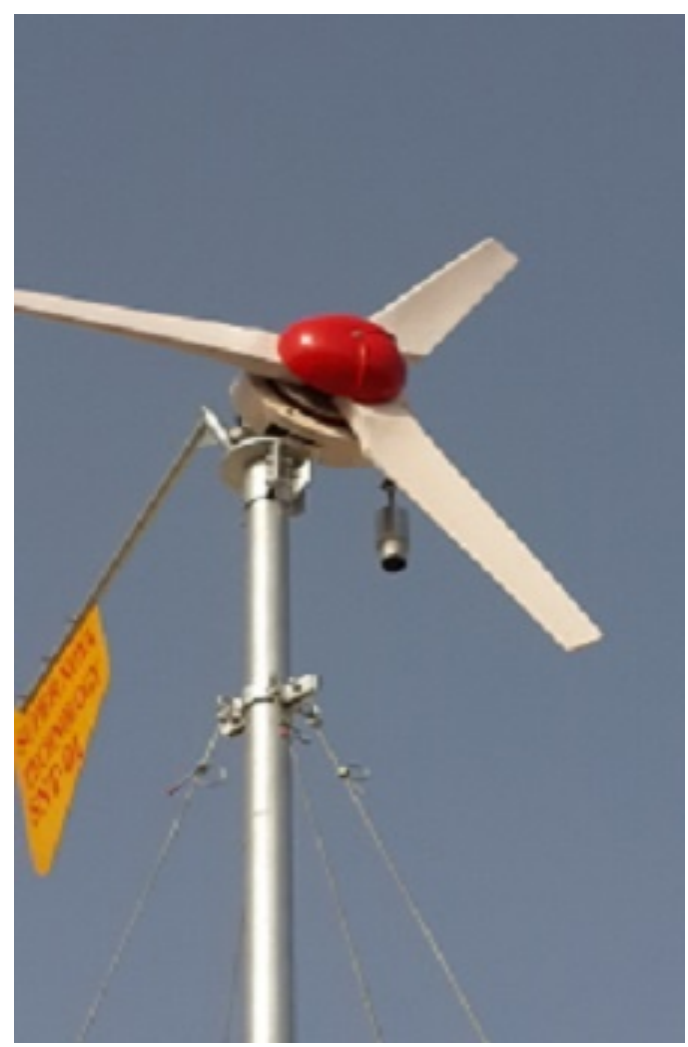

Figure 10. 0.7 kW SNT-1 rooftop wind turbine installed at GERMI rooftop.

specially designed for low wind speed regime and for the first time attempted and installed a grid tied rooftop micro wind turbine. Further improvement is needed to reach to a level to work on concrete proof. We need to test our suggested method's usefulness to the society as well as to the industry. In this respect, more exhaustive experiments could be devised with data logging facilities. The wind braking and motor system will be upgraded and automated in near future for better results. A control system could also be attached which disconnects the generator to grid when the grid supply is off. During the monsoon season, when the wind velocity is fair enough, our method can be a real asset at least for rooftop wind turbines [14]. The only limitation being it will be commercially beneficial only when the wind speed ranges from 3 to $6 \mathrm{~m} / \mathrm{s}$. 


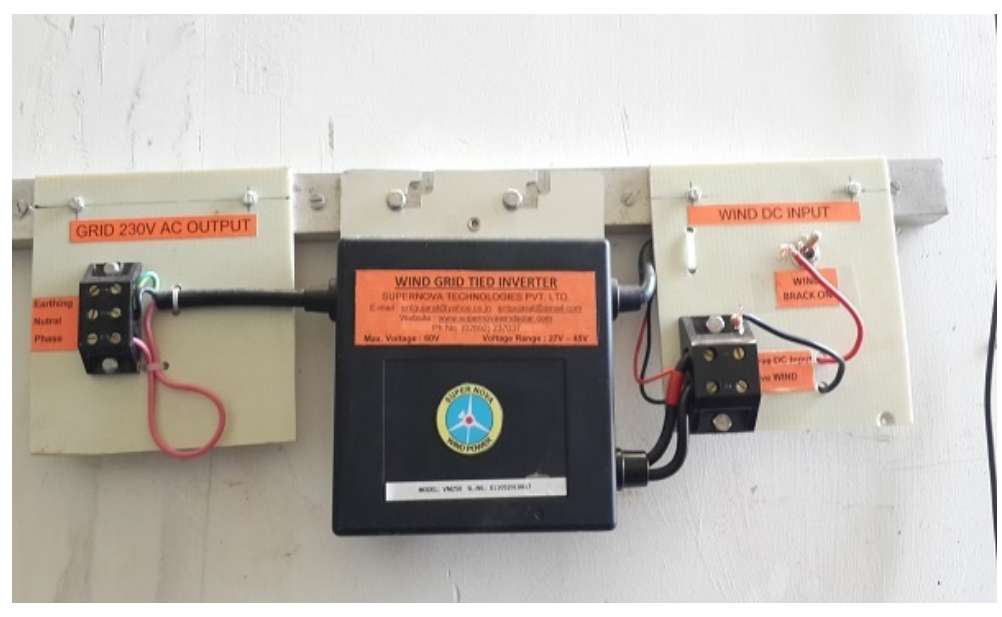

Figure 11. Grid tied inverter for SNT-1 wind turbine.

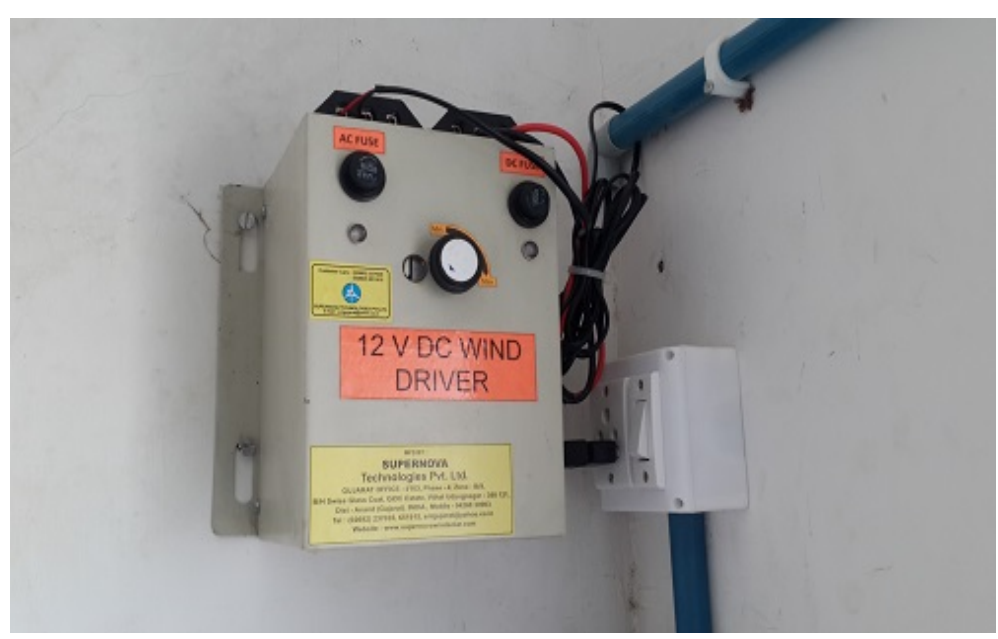

Figure 12. Variac for external 12V DC Motor.

\section{Acknowledgements}

We would like to thank all the GERMI staff for their full cooperation to execute this task. Full support provided by Dr. Sagar Agarvat, Scientist C, Solar Research Wing, GERMI is greatly acknowledged. His coordination and help is very much appreciated without which we could have not completed this work. Thanks are due to Mr. Manyam Telukuntla from UPES Dehradun, a summer intern student at GERMI for assisting in the experimental work. Mr. Ankur Bhatnagar, Mr. Dharmik Lay, Mr. Prashant Gopiyani, Mr. Nilesh Patel and Mrs. Sandhya Radhakrishnan have helped in many ways for successful completion of this project.

\section{References}

[1] Christiner, M., Dobbins, R., Ndegwa, A. and Sivak, J. (2010) Rooftop Wind Turbine Feasibility in Boston, Massachusetts. Worcester Polytechnic Institute, Worcester.

[2] Jha, S.N. and Gandhi, J.R. (2006) Low RPM, High Torque Small Wind Generator for Hybrid System. http://www.ibrarian.net/navon/paper/Low_RPM_High_Torque_Small_Wind_Generator_for_Hy.pdf?paperid=76511 62

[3] Indian Wind Energy and Economy. www.Indianwindpower.com

[4] Centre for Wind Energy Technology (C-WET), Chennai. http://www.cwet.tn.nic.in

[5] Burton, T., et al. (2001) Wind Energy Handbook. John Wiley \& Sons, Ltd., Hoboken.

[6] Ahmed, S. (2010) Wind Energy: Theory and Practice, Department of Mechanical Engineering, MNNIT Bhopal, Pren- 
tice Hall of India, New Delhi.

[7] Johnson, G.L. (2001) Wind Energy Systems. Kansas State University

[8] Ragheb, M. (2014) Optimal Rotor Tip Speed Ratio. http://mragheb.com/NPRE\%20475\%20Wind\%20Power\%20Systems/Optimal\%20Rotor\%20Tip\%20Speed\%20Ratio.p df

[9] McCosker, J. (2012) Design and Optimization of a Small Wind Turbine. Rensselaer Polytechnic Institute, Troy, NY.

[10] Ragheb, M. and Ragheb, A.M. (2011) Wind Turbines Theory-The Betz Equation and Optimal Rotor Tip Speed Ratio. Fundamental and Advanced Topics in Wind Power, Dr. Rupp Carriveau (Ed.), InTech.

http://www.intechopen.com/books/fundamental-and-advanced-topicsin-wind-power/wind-turbines-theory-the-betz-equ ation-and-optimal-rotor-tip-speed-ratio

[11] Predescu, M., Bejinariu, A., Mitroi, O. and Nedelcu, A. (2009) Influence of the Number of Blades on the Mechanical Power Curve of Wind. International Conference on Renewable Energies and Power Quality (ICREPQ'09), Valencia, 15-17 April 2009, 6p.

[12] Sarkar, A. and Behera, D.K. (2012) Wind Turbine Blade Efficiency and Power Calculation with Electrical Analogy. International Journal of Scientific and Research Publications, 2, 1-5.

[13] Martinez, J. (2007) Modelling and Control of Wind Turbines. https://workspace.imperial.ac.uk/centreforprocesssystemsengineering/Public/MSc\%20Thesis/2007\%20MSc\%20Thesis 2007.2\%20-\%20Martinez\%20Jasmin.pdf

[14] Rivkin, D.A. and Silk, L. (2013) Wind Energy (Art and Science of Wind Power). Jones \& Bartlett Learning, Burlington, Mass. 
Scientific Research Publishing (SCIRP) is one of the largest Open Access journal publishers. It is currently publishing more than 200 open access, online, peer-reviewed journals covering a wide range of academic disciplines. SCIRP serves the worldwide academic communities and contributes to the progress and application of science with its publication.

Other selected journals from SCIRP are listed as below. Submit your manuscript to us via either submit@scirp.org or Online Submission Portal.
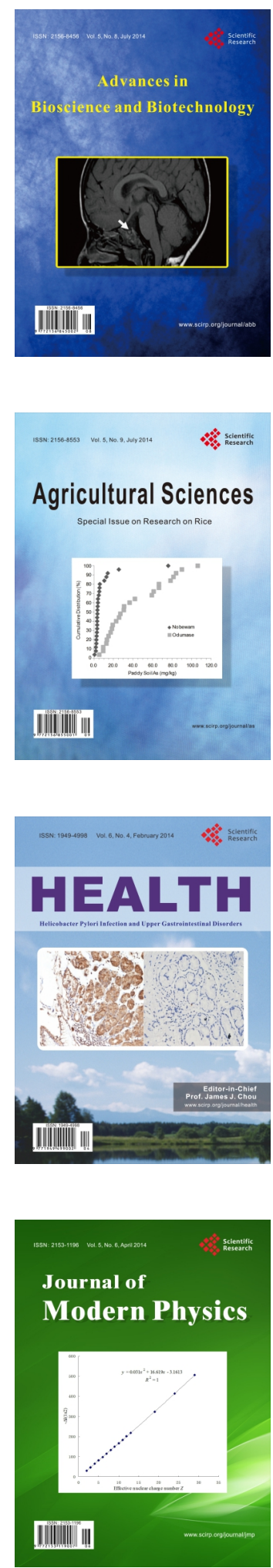
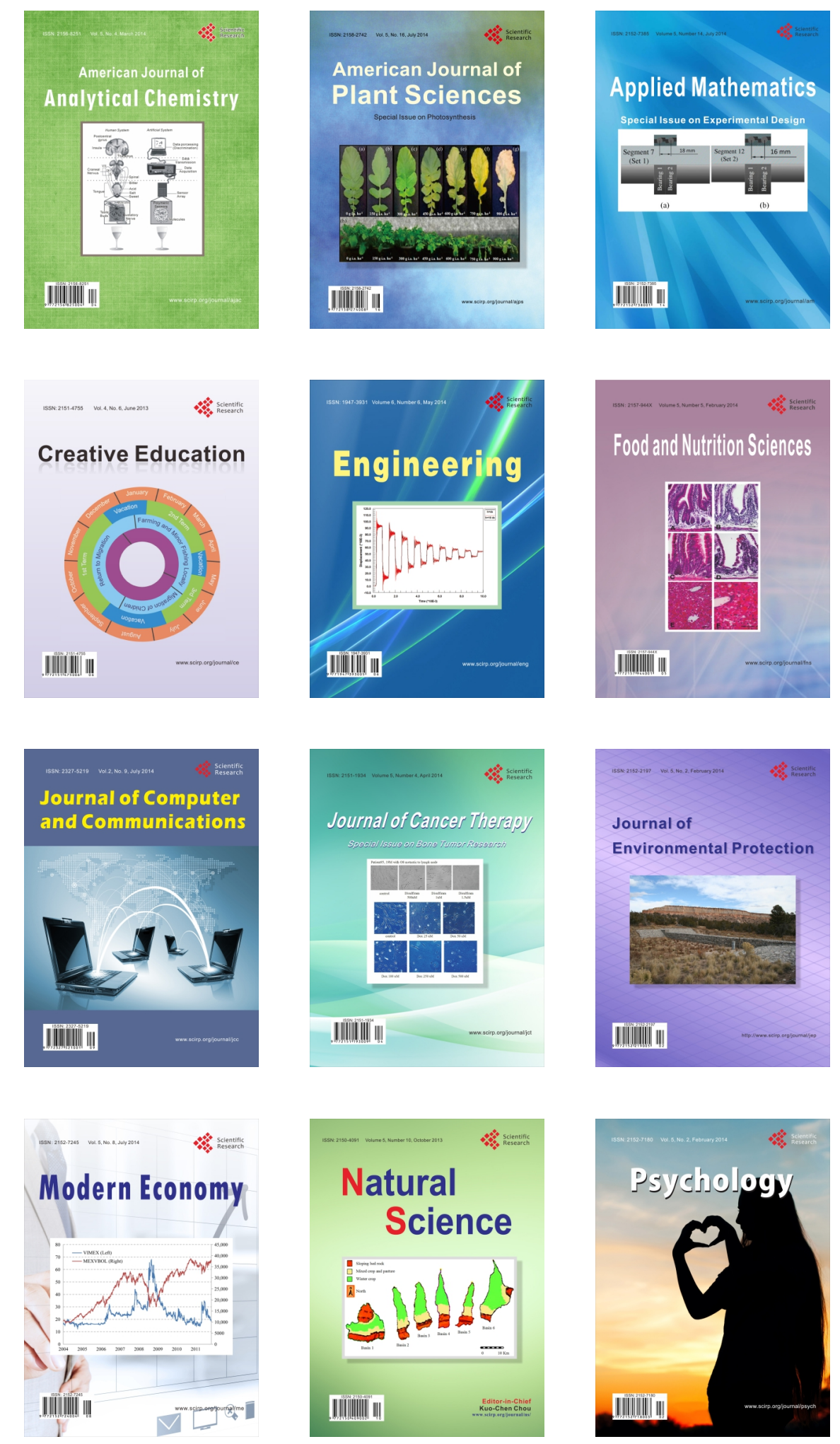